\title{
IMPACT OF SPORTS ON HEALTH OF FORMER PROFESSIONAL SOCCER PLAYERS IN BRAZIL
}

\author{
Gustavo Gonçalves Arlanil ${ }^{1}$, Paulo Schmith Lara ${ }^{1}$, Diego Costa Astur ${ }^{1}$, Molses Cohen $^{1}$, João Paulo Pontes Gonçalves ${ }^{1}$, Mario Ferretti $^{1}$
}

\section{ABSTRACT}

Objective: To evaluate the social, economic and health aspects related to former professional soccer players in Brazil. Methods: This was a cross-sectional study with the participation of 100 male Brazilian former professional soccer players. For characterization of the sample variables such as age, current and past weight, height, BMI (Body Mass Index) and player position were evaluated. In all analyzes it was considered $\mathrm{P}<0.05$. Results: In the group of former players evaluated, $78 \%$ were overweight and $4 \%$ were considered obese. During their careers, $54 \%$ of now ex-soccer players underwent drugs infiltration in the knee. Currently, former athletes presented on average 5.4 points on the VAS pain scale, with $97 \%$ of ex-players complaining of knee pain. Conclusion: The results of this study show that these individuals had large weight gain after retirement, high frequency of drug injections in the knee during their careers and chronic pain in this joint after retirement. Level of Evidence III, Cross-Sectional Study.

Keywords: Osteoarthritis. Knee. Soccer. Retirement.

Citation: Arliani GG, Lara PS, Astur DC, Cohen M, Gonçalves JPP, Ferretti M. Impact of sports on health of former professional soccer players in Brazil. Acta Ortop Bras. [online]. 2014;22(4):188-90. Available from URL: http://www.scielo.br/aob.

\section{INTRODUÇÃO}

Football is undoubtedly the most popular sport in the world. This modality currently has about 200,000 professional athletes and 240 million amateur players of which approximately $80 \%$ are of the masculine gender. ${ }^{1,2}$

The athlete practitioner of this sport is constantly exposed to musculoskeletal injuries. When compared to industry workers, the risk of injury showed to be 1,000 times more frequent among football players. ${ }^{3}$ Moreover, in recent years the professional athlete has been increasingly demanded. The number of games and championships is increasing, which requires large proportion of athletes to work on their maximum performance, increasing the risk of new injuries. ${ }^{4,5}$

The association of football with possible sequelae due to injuries after retirement and exaggerated practice of sport is one of the most discussed topics nowadays. Currently it is often discussed injury prevention in order to reduce their incidence. However, a deep understanding of the epidemiology of the sport is needed, in order to perform efficient preventive measures. Furthermore, it is through epidemiological studies that the problems' characteristics that need to be faced to preventing these injuries are established. ${ }^{6}$

The high number of practitioners and the importance of related social and economic aspects associated to the lack of published literature on the subject make it extremely relevant to assessing the current condition of these retired former professional players.

The objective of this study is to assess the various social, economic and health aspects regarding former professional soccer players in Brazil. From the results of this study we will determine potential problems that must be faced in preventing injuries and sequelae of this sport.

\section{MATERIAL E MÉTODOS}

The study was approved by the Ethics and Research Committee (CEP 0629/10) of Universidade Federal de São Paulo and a term of informed consent was signed by all participants.

This is a cross-sectional study conducted from January to December 2013. Participants were 100 former professional football players of Brazil of the masculine gender. The former athletes were recruited randomly in a pool of former association of professional football players.

Were included in the study Brazilian male former professional football players of Brazilian's football first range teams, aged between 30 and 70 years old, with at least 5 years of professional career with participation in training and games during this period were included. Former players who did not wish to participate in the study or refused to sign the informed consent term (TCLE) were excluded.

For clinical characterization of the sample was evaluated age,

All the authors declare that there is no potential conflict of interest referring to this article.

1. Department of Orthopedics and Traumatology, Universidade Federal de São Paulo, São Paulo, SP, Brazil.

Work developed at Sports Traumatology Center, Department of Orthopedic and Traumatology, Universidade Federal de São Paulo, São Paulo, SP, Brazil. Correspondence: Rua Borges Lagoa, 783, $5^{\circ}$ andar, 04038-032, São Paulo, SP, Brazil. drgustavoarliani@gmail.com 
current weight and weight by the time as professional athlete, height, BMI (Body Mass Index), position in which he played, dominance in the lower limbs, career duration (years), injuries suffered and surgeries during professional career, current participation in recreational soccer games, medicine infiltration in the knee during his career and current occupation.

The quantification of the current existing pain in the knees was performed by Visual Analogue Scale (VAS) adapted to one side of a $100 \mathrm{~mm}$ millimeter ruler. The individual was asked to only score a painful sensation in the knees (after explaining that the line referred to what he felt about the pain) starting at zero, i.e., absence of pain, up to $100 \mathrm{~mm}$, for maximum pain. Thus, we measured in the millimeter ruler from 0-10, quantifying pain scale of each participant.

\section{Statistical Analysis}

We described the qualitative characteristics of former players with absolute and relative frequencies and quantitative characteristics with summary measures (mean, standard deviation, median, minimum and maximum, or quartiles). Current body weights and BMI were compared with data by the time of professional performance using the paired Student t-test and Pearson's correlation to assess the correlation between these variables. The Visual Analogue scale for pain (VAS) was compared across categories using the Mann-Whitney test and according to BMI categories using the Kruskal-Wallis test and calculated the correlation of VAS with career length using Pearson's correlation. In all analyzes a value of $P<0.05$ was considered. Statistical analysis was performed using software SPSS version 18.0

\section{RESULTS}

The former players who took part at the sample worked, during their careers, in the following positions: Goalkeeper (9\%); Defender (31\%); Midfielders (44\%) and Striker (16\%). Regarding the dominance of lower limbs, we found that $74 \%$ of these former athletes were right-footed. The mean age of the ex-professionals was 46.2 years old $(S D=7.1)$ and their careers lasted, on average, 17.20 years (median: 17 years). The distribution of injuries and knee surgeries, suffered by individuals in the sample during their career and current comorbidities are described in Table 1. BMI of former football players was, on average, at the time they acted professionally, $23.6(S D=1.3)$ $\mathrm{kg} / \mathrm{m}^{2}$ rising to $26.4(\mathrm{SD}=2.1) \mathrm{kg} / \mathrm{m}^{2}$ currently ( $\left.<<0.001\right)$. In the group of former players evaluated, $78 \%$ were overweight (BMI between 25 and $30 \mathrm{~kg} / \mathrm{m}^{2}$ ) and $4 \%$ were classified as

Table 1. Description of qualitative characteristics of former football players.

\begin{tabular}{c|c|c}
\hline Variable & N & $\%$ \\
\hline Knee injuries & & \\
\hline No & 34 & 34 \\
\hline Yes & 66 & 66 \\
\hline Knee Surgerie & & \\
\hline No & 63 & 63 \\
\hline Yes & 37 & 37 \\
\hline CM & & \\
\hline No & 82 & 82 \\
\hline Yes & 18 & 18 \\
\hline Total & 100 & 100
\end{tabular}

Acta Ortop Bras. 2014;22(4):188-90 obese $\left(\mathrm{BMl}>30 \mathrm{~kg} / \mathrm{m}^{2}\right)$. During their careers, $54 \%$ of ex-football players underwent medicine infiltrations in the knee with a mean of 1.9 injections per athlete (median: 1). Regarding knee pain, former athletes had an average of 5.4 points $(S D=2.5)$ in the VAS scale, and $97 \%$ of the ex-players complained of knee pain. The correlation of VAS with other variables is shown in Table 2. Of this sample of former players, $64 \%$ are still currently practicing football recreationally. Most retired players (88\%) currently have other professions, and the vast majority (66\%) work in jobs related to football (coach, commentator, entrepreneur, etc.).

\begin{tabular}{|c|c|c|c|c|c|c|c|}
\hline VAS & & & & & & & \\
\hline Variable & Mean & St. Dev. & Median & P25 & P75 & N & $p$ \\
\hline Current BMI (kg/m2) & & & & & & & $0,341^{*}$ \\
\hline 20 a 25 & 4,64 & 2,32 & 5 & 3,13 & 5,25 & 18 & \\
\hline 25 a 30 & 5,58 & 2,52 & 6 & 3 & 8 & 78 & \\
\hline$>30$ & 4,38 & 3,59 & 4,75 & 0,75 & 7,63 & 4 & \\
\hline Knee Injuries & & & & & & & $<0,001$ \\
\hline No & 3,43 & 1,78 & 3 & 3 & 4 & 34 & \\
\hline Yes & 6,36 & 2,29 & 7 & 5 & 8 & 66 & \\
\hline Knee Surgeries & & & & & & & $<0,001$ \\
\hline No & 4,51 & 2,09 & 4 & 3 & 6 & 63 & \\
\hline Yes & 6,82 & 2,59 & 8 & 4,75 & 9 & 37 & \\
\hline $\mathrm{CM}$ & & & & & & & 0,117 \\
\hline No & 5,17 & 2,56 & 5 & 3 & 7,13 & 82 & \\
\hline Yes & 6,25 & 2,29 & 7 & 4,13 & 8 & 18 & \\
\hline Football today & & & & & & & 0,041 \\
\hline No & 6,11 & 2,67 & 6,5 & 3,25 & 8 & 36 & \\
\hline Yes & 4,95 & 2,38 & 5 & 3 & 7 & 64 & \\
\hline Infiltrations & & & & & & & $<0,001$ \\
\hline No & 3,63 & 1,72 & 3,5 & 3 & 5 & 46 & \\
\hline Yes & 6,84 & 2,16 & 7 & 6 & 8 & 54 & \\
\hline Works currently & & & & & & & 0,638 \\
\hline No & 5,04 & 2,93 & 5,5 & 2,25 & 7,38 & 12 & \\
\hline No & 5,41 & 2,50 & 5,5 & 3 & 7,88 & 88 & \\
\hline
\end{tabular}

Result of Mann-Whitney test; * Result of Kruskal-Wallis test.

\section{DISCUSSION}

This study revealed some important changes in the ex-football players evaluated: there was a significant weight gain after retirement, high number of medicine injections in the knee during their professional careers, and chronic pain in this joint. The transition from active to retired player is a challenge for any professional athlete, and perhaps even greater for a soccer player in Brazil. The prospect of lack of activities to perform the next day associated with low retirement age of these individuals is disturbing. Regarding health, there are doubts regarding the quality of life, pain and possible sequelae related to high performance sports. A study in the United Kingdom with ex-professional football players showed that ex-athletes diagnosed with osteoarthritis of the knees had a worse health-related quality of 
life, also resulting in the need for specific medical treatment for such illnesses. ${ }^{7}$ The same study assessing ex-football players showed that $32 \%$ of subjects underwent some surgery during their careers in sports. In our study, $97 \%$ of subjects had some pain in knees with an average of 5.4 points on the Visual analog scale for pain (VAS). Of these, $66 \%$ of the ex-players had diagnosed injuries, and $37 \%$ previously performed some surgery on the knee during their career. Some studies have correlated the injury of the anterior cruciate ligament and meniscectomy with an increased risk of developing osteoarthritis compared to players with no injuries. ${ }^{8}$ However, Appel et al. ${ }^{9}$ suggest that only sports practice sets up a risk factor for osteoarthritis of the knees even without injuries. In the present study, athletes who during their career suffered knee injuries, were submitted to knee surgery, or were subjected to infiltration showed higher VAS values, i.e., complained of pain more intensely. We found out in our study, moreover, an increase in body weight and body mass index (BMI) of athletes after retirement. According to Reijman et al. ${ }^{10}$ high body mass indexes further increase the risk of pain and symptomatic osteoarthritis in the knees. In another study of former soccer players, $80 \%$ of them presented with overweight. ${ }^{11}$ This association between overweight and joint degeneration makes the athlete's situation even more troubling after retirement, since he is not prepared for such a situation.
Furthermore, 54\% of ex-football players evaluated in this study underwent knee infiltration of medicines during their careers. We know that these infiltrations are usually held in injured players so that they can play important matches even though this procedure might mask athlete's pain and worsen existing injuries. The results of this study indicate some important data and some adverse effects of professional football practice. We consider extremely important defining and discussing the correlation between football and these negative outcomes, in order to develop solution plans for these problems or reducing their effects. One of the weaknesses of our study is the large age heterogeneity of the sample, a fact that may create an assessment bias of our findings, that changes could be related to age and not to sports practice. Another limitation of our study is the absence of a control group for comparison.

\section{CONCLUSION}

The results of this study involving the evaluation of former professional football players in Brazil showed that these individuals had large weight gain after retirement, a high rate of medicine injections in the knee during their professional activity, and chronic pain in this joint after career termination. Moreover, it showed that the vast majority of former players of Brazil continue working in jobs directly related to football.

\section{REFERÊNCIAS}

1. Junge A, Dvorak J. Soccer injuries: a review on incidence and prevention. Sports Med. 2004;34(13):929-38.

2. Timpka T, Risto O, Björmsjö M. Boys soccer league injuries: a community-based study of time-loss from sports participation and long-term sequelae. Eur J Public Health. 2008;18(1):19-24.

3. Hawkins RD, Fuller CW. A prospective epidemiological study of injuries in four English professional football clubs. Br J Sports Med. 1999;33(3):196-203.

4. Maffulli N, Longo UG, Gougoulias N, Caine D, Denaro V. Sport injuries: a review of outcomes. Br Med Bull. 2011;97:47-80.

5. Molloy MG, Molloy CB. Contact sport and osteoarthritis. Br J Sports Med. 2011;45(4):275-7.

6. Brooks JH, Fuller CW. The influence of methodological issues on the results and conclusions from epidemiological studies of sports injuries: illustrative examples. Sports Med. 2006;36(6):459-72.
7. Turner AP, Barlow JH, Heathcote-Elliott C. Long term health impact of playing professional football in the United Kingdom. Br J Sports Med. 2000;34(5):332-6.

8. Lohmander LS, Englund PM, Dahl LL, Roos EM. The long-term consequence of anterior cruciate ligament and meniscus injuries: osteoarthritis. Am J Sports Med. 2007;35(10):1756-69.

9. Appel H. Late results after meniscectomy in the knee joint. A clinical and roentgenologic follow-up investigation. Acta Orthop Scand Suppl. 1970;133:1-111.

10. Reijman M, Pols HA, Bergink AP, Hazes JM, Belo JN, Lievense AM, et al Body mass index associated with onset and progression of osteoarthritis of the knee but not of the hip: the Rotterdam Study. Ann Rheum Dis. 2007;66(2):158-62

11. Elleuch MH, Guermazi M, Mezghanni M, Ghroubi S, Fki H, Mefteh S, et al. Knee osteoarthritis in 50 former top-level soccer players: a comparative study. Ann Readapt Med Phys. 2008;51(3):174-8. 